\title{
Anti-Inflammatory Effect of 3-Bromo-4,5-Dihydroxybenzaldehyde, a Component of Polysiphonia morrowii, In Vivo and In Vitro
}

\author{
Na-Jin Kang', Sang-Chul Han', Hyun-Jae Kang', Geum Ko', Weon-Jong Yoon ${ }^{2}$, \\ Hee-Kyoung Kang' and Eun-Sook Yoo' \\ ${ }^{1}$ Department of Medicine, School of Medicine, Jeju National University, Jeju, Korea \\ ${ }^{2}$ Jeju Biodiversity Research Institute (JBRI), Jeju Technopark (JTP), Jeju, Korea
}

\begin{abstract}
3-Bromo-4,5-dihydroxybenzaldehyde (BDB) is a natural bromophenol compound that is most commonly isolated from red algae. The present study was designed to investigate the anti-inflammatory properties of BDB on atopic dermatitis (AD) in mice induced by 2,4-dinitrochlorobenzene (DNCB) and on lipopolysaccharide (LPS)-stimulated murine macrophages. BDB treatment $(100 \mathrm{mg} / \mathrm{kg})$ resulted in suppression of the development of $\mathrm{AD}$ symptoms compared with the control treatment (induction-only), as demonstrated by reduced immunoglobulin E levels in serum, smaller lymph nodes with reduced thickness and length, a decrease in ear edema, and reduced levels of inflammatory cell infiltration in the ears. In RAW 264.7 murine macrophages, BDB $(12.5,25,50$, and $100 \mu \mathrm{M})$ suppressed the production of interleukin- 6 , a proinflammatory cytokine, in a dose-dependent manner. BDB also had an inhibitory effect on the phosphorylation of nuclear factor kappa-light-chain-enhancer of activated B cells (NF- $\kappa \mathrm{B})$ and signal transducer and activator of transcription 1 (STAT1; Tyr 701), two major signaling molecules involved in cellular inflammation. Taken together, the results show that BDB treatment alleviates inflammatory responses in an atopic dermatitis mouse model and RAW 264.7 macrophages. These results suggest that BDB may be a useful therapeutic strategy for treating conditions involving allergic inflammation such as atopic dermatitis.
\end{abstract}

Key words: 3-Bromo-4,5-dihydroxybenzaldehyde, Inflammation, Atopic dermatitis, 2,4-Dinitrochlorobenzene, Immunoglobulin E, Interleukin-6

\section{INTRODUCTION}

Allergic skin inflammation, such as atopic dermatitis, is characterized by skin barrier dysfunction, edema, and infiltration of various types of inflammatory cells. Atopic dermatitis $(\mathrm{AD})$ is a chronic skin disease associated with skin hyper-reactivity, including edema and itching, which affects

Correspondence to: Eun-Sook Yoo, Department of Medicine, School of Medicine, Jeju National University, Jeju 63243, Korea E-mail: eunsyoo@jejunu.ac.kr

Abbreviations: BDB, 3-Bromo-4,5-dihydroxybenzaldehyde; $A D$, Atopic dermatitis; DNCB, 2,4-Dinitrochlorobenzene; IgE, Immunoglobulin $\mathrm{E} ; \mathrm{NF}-\kappa \mathrm{B}$, Nuclear factor kappa-light-chain-enhancer of activated B cells; STAT, Signal transducer and activator of transcription 1.

This is an Open-Access article distributed under the terms of the Creative Commons Attribution Non-Commercial License (http:// creativecommons.org/licenses/by-nc/3.0) which permits unrestricted non-commercial use, distribution, and reproduction in any medium, provided the original work is properly cited. approximately $10 \sim 20 \%$ of children and $1 \sim 3 \%$ of adults worldwide (1). This systemic disorder is characterized by thickening of the papillary dermis, parakeratosis, skin barrier dysfunction, epidermal hyperplasia, severe skin dehydration, and T-cell hyper-proliferation. The skin lesions in $\mathrm{AD}$ patients are characterized by the proliferation and infiltration of various inflammatory cells, especially eosinophils, mast cells, basophils, and T-cells $(2,3)$.

Mast cells play an important role in inflammatory and anaphylactic reactions. Cross-linking with Fc3RI, the highaffinity surface receptor for immunoglobulin E (IgE), activates mast cells, causing them to secrete a variety of inflammatory mediators, such as cytokines, serotonin, and histamine $(4,5)$.

T-cells are a type of lymphocytes that play a key role in cell-mediated immunity. These cells can differentiate into one of several subtypes, such as T-helper 1 (Th1), Th2, Th9, Th17, and regulatory T-cells, all of which express different types of cytokines to facilitate different immune responses. Chronic AD is characterized by Th1-mediated immune 
responses. Th1 cells, which are regulated by the transcription factor T-box expressed in T-cells (T-bet), express large amounts of interferon-gamma (IFN- $\gamma$ ), which can suppress the development of Th2 cells $(6,7)$. Acute AD is characterized by Th2-mediated immune responses. Th2 cells, which are regulated by GATA-binding protein-3 (GATA-3), secrete a variety of cytokines, such as interleukin-4 (IL-4), IL-5, IL-6, IL-9, and IL-13, which regulate the development of Th1 cells $(8,9)$.

IL-6 is well known as a multifunctional cytokine and is a soluble mediator of inflammatory responses, immune responses, and a variety of biological functions. Previous studies have shown that IL-6 is involved in various diseases, including rheumatoid arthritis, and that IL-6 amplifies Toll-like receptor (TLR)-induced cytokine and chemokine production during inflammatory responses, such as those associated with rheumatic inflammatory disease. IL-6 is also produced by many cell types and is regulated by various receptors, including cytokine receptors, antigen receptors, and TLRs (10-16). Upon stimulation with inflammatory agents, LPS binding initiates cell activation via kinase cascades, such as those involving the TLR member TLR4 and downstream signaling mechanisms. LPS-mediated TLR4 signaling activates the nuclear factor- $\kappa \mathrm{B}(\mathrm{NF}-\kappa \mathrm{B})$ complex and signal transducer and activator of transcription 1 (STAT1) in macrophages, monocytes, astrocytes, and other cells. These signaling pathways are responsible for TLRmediated induction of inflammatory cytokines and changes in gene expression, including expression of IL-6 (17-25).

Recent studies have investigated the active components of several natural marine resources to identify novel pharmaceutical applications and nutritional value (26-29). Several previous studies examined the anti-allergenic effects of 3-bromo-4,5-dihydroxybenzaldehyde (BDB) isolated from marine red algae, including Polysiphonia morrowii and $P$. urceolata. BDB protects human keratinocytes against UVBinduced oxidative stress by scavenging ROS and has potential as an antiviral therapeutic agent in fish $(30,31)$. The beneficial effects of BDB have been described in many studies; however, the mechanism by which it modulates the immune system and inflammatory reactions is poorly understood. Therefore, the aim of the present study was to examine whether BDB suppresses a variety of inflamma-

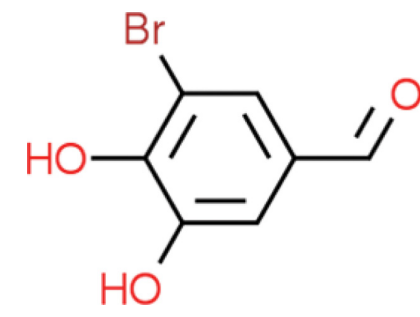

Fig. 1. Chemical structure of 3-bromo-4,5-dihydroxybenzaldehyde (BDB) from Polysiphonia urceolata. tory responses. The ability of BDB to modulate inflammatory reactions was investigated using a mouse model of $\mathrm{AD}$ and murine macrophages.

\section{MATERIALS AND METHODS}

Reagents. BDB (purity $>95 \%$ ) was purchased from Matrix Scientific (Colombia, SC, USA). 3-Bromo-4,5-dihydroxybenzaldehyde (BDB) was purchased from Matrix Scientific (Colombia SC) and the purity of BDB is $>95$ percent (Fig. 1). 2,4-Dinitrochlorobenzene (DNCB) was purchased from Tokyo Kasei Kogyo (Tokyo, Japan). LPS (E. coli 0111:B4) was purchased from Sigma-Aldrich Chemical Co (St. Louis, MO, USA). Fetal bovine serum (FBS) and Dulbecco's modified Eagle's medium (DMEM) were obtained from Invitrogen-GIBCO (Grand Island, NY, USA). Mouse IL-6 Duoset enzyme-linked immunosorbent assay (ELISA) kits were obtained from R\&D Systems (St. Louis, MO, USA). Phospho-STAT1 antibodies (Tyr701 and Ser727) and NF- $\mathrm{B}$ p65 and phospho-p65 antibodies were purchased from Cell Signaling Technology (Beverly, MA, USA); NF$\kappa \mathrm{B}$ p50 (E-10) antibody was purchased from Santa Biotechnology, Inc. (Santa Cruz, CA, USA); anti-STAT1 was purchased from Becton Dickinson (San Diego, CA, USA); and anti- $\beta$-actin was obtained from Sigma-Aldrich Chemical Co. All other reagents were of reagent grade.

Experimental animals. BALB/c mice (female, 7-weeksold) were purchased from Orient Bio (Orient Bio Inc., Seongnam, Korea) and maintained under pathogen-free conditions in the animal facility of Jeju National University. All animal experiments were approved by the Jeju National University Animal Care and Use Committee.

DNCB application to induce AD. Mice were divided into four groups ( $\mathrm{n}=5$ per group): saline (normal), AD (induction-only), $\mathrm{AD}+$ Hydrocort cream, and $\mathrm{AD}+\mathrm{BDB}$. Mice were sensitized by spreading $1 \%$ DNCB or vehicle (an acetone:olive oil mixture [3:1 vol/vol]) on their abdomen as the first sensitization (day 0 ). On day 7 , mice were challenged again by applying $0.3 \%$ DNCB to the ears on every other day for 30 days. Starting on day 19, the mice were treated with hydrocort cream (Green Cross, Korea) containing $2 \mathrm{mg} / \mathrm{g}$ hydrocortisone valerate and BDB (2.5 $\mathrm{mg}$ in acetone; $30 \mu \mathrm{L} / \mathrm{ear}$ ), which was applied on their ears every other day $(32,33)$. The mice were killed on day 38 , and the mandibular lymph nodes (LNs) were photographed to record morphological changes.

Macroscopic edema and histology. In the experimental AD mouse model, DNCB stimulation elicited ear edema, and ear thickness was measured using a digital thickness gauge (Mitutoyo, Kawasaki, Japan). Ear tissues were fixed in 10\% formalin, and then embedded in paraffin. Paraffin sections 
( $3 \mu \mathrm{m}$ each) were stained with hematoxylin and eosin (H\&E).

Cell culture and cell viability. Murine macrophage RAW 264.7 cells were obtained from the American Type Culture Collection (ATCC, Rockville, MD, USA). Cells were cultured in DMEM supplemented with $10 \%$ (vol/vol) FBS and $100 \mathrm{U} / \mathrm{mL}$ penicillin-streptomycin (GIBCO, Grand Island, NY, USA). The cells $\left(1.5 \times 10^{5}\right.$ cells $\left./ \mathrm{mL}\right)$ were preincubated with DMEM/10\% FBS for $18 \mathrm{hr}$. Cell viability was then determined from the culture supernatants of cells treated with LPS $(1 \mu \mathrm{g} / \mathrm{mL})$ in the absence or presence of BDB (100 mM in dimethyl sulfoxide; $12.5,25,50,100 \mu \mathrm{M} /$ group) for $24 \mathrm{hr}$. The cells were maintained in $5 \% \mathrm{CO}_{2}$ humidified atmosphere at $37^{\circ} \mathrm{C}$ in an incubator. Cell viability was determined using EZ-CyTox (WST-1) assays (itsBIO, Korea) following the manufacturer's protocol. The light absorbance of each well was quantified using a VersaMax ELISA microplate reader (Molecular Devices, CA, USA) at $450 \mathrm{~nm}$.

ELISA. The production of IL-6 proteins was measured using ELISA kits following the manufacturer's protocol. The optical density was measured using a VersaMax ELISA microplate reader at $450 \mathrm{~nm}$.

Western blot analysis. The cells were washed twice with ice-cold phosphate-buffered saline (PBS). The cells were lysed in the lysis buffer (iNtRON Biotechnology, Gyeonggi, Korea) for $30 \mathrm{~min}$ on ice. Protein in the supernatant was quantified using the Bradford assay (Bio-rad, Herculers, CA, USA). Aliquots of the lysates were separated on a NuPAGE $4 \sim 12 \%$ bis-Tris gel (Invitrogen, Carlsbad, CA, USA). The proteins were transferred onto a polyvinylidene difluoride (PVDF) membrane using an iBlot gel transfer device (Invitrogen). Membranes were blocked with 5\% non-fat skim milk diluted in Tween 20-tris buffered saline (TTBS), and the membranes were incubated with primary antibodies diluted in $1 \%$ bovine serum albumin (BSA)TTBS buffer at $4^{\circ} \mathrm{C}$ overnight. After washing, the membrane was incubated with secondary HRP-linked anti-rabbit or anti-mouse $\mathrm{IgG}$ respectively for $90 \mathrm{~min}$ at room temperature. After washing again, immunoactive proteins were detected with WEST-ZOL (plus) western blot detection system (iNtRON Biotechnology) following the manufacturer's instructions.

Statistical analysis. Quantity One version 4.2.1 and Image-Pro plus version 4.5 software (Bio-rad) were used to transform images into numerical values. Student's t-test and two-way analysis of variance (ANOVA) were used to determine the statistical significance of differences between experimental and control groups. Data are shown as mean \pm standard deviation. The $p$-values less than 0.05 indicated statistical significance.
(A)

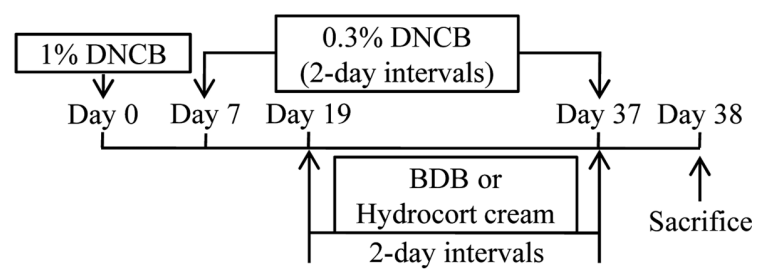

(B)

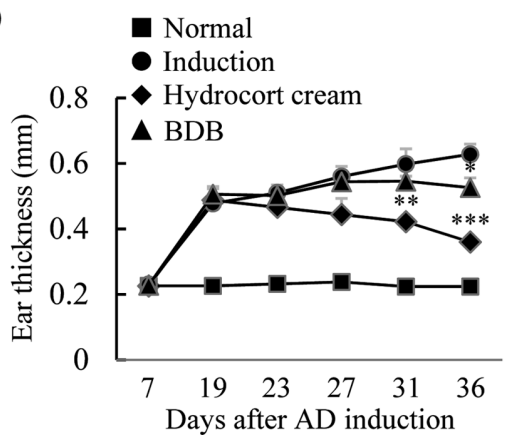

Fig. 2. 3-Bromo-4,5-dihydroxybenzaldehyde (BDB) suppresses the expression of serum lgE. (A) Mice were sensitized by applying 1\% 2,4-dinitrochlorobenzene (DNCB) or vehicle on their abdomen (day 0). On day 7, mice were challenged again by applying $0.3 \%$ DNCB to the ears every other day for up to 30 days. Starting on day 19 , the mice were treated with hydrocort cream and BDB $(100 \mathrm{mg} / \mathrm{kg})$ on their ears every other day. The mice were killed on day 38. (B) After killing, lgE levels in mouse serum were measured by ELISA. AD: atopic dermatitis. Data are representative of 5 mice per group. Values represent the mean \pm SD. ${ }^{*} p<0.05,{ }^{* *} p<0.01$ and ${ }^{* * *} p<0.001$ compared to mice stimulated with DNCB alone (induction group).

\section{RESULTS}

BDB decreases serum IgE levels. To experimentally induce $\mathrm{AD}$, mice were subjected to an initial sensitization with $1 \%$ DNCB applied to the abdomen. They were then resensitized by applying $0.3 \%$ DNCB to the ears every other day for up to 30 days. Starting on day 19 , the mice were treated with hydrocortisone cream and BDB $(100 \mathrm{mg} / \mathrm{kg})$ on the ears every other day. All mice were killed on day 38 (Fig. 2A). $\operatorname{IgE}$ is a crucial therapeutic target for $\mathrm{AD}$ because it is the major activator of mast cells, which release histamine, tryptase, and cytokines (34). Therefore, we measured serum IgE levels in AD mice using ELISA. The BDBtreated group had significantly decreased levels of $\operatorname{IgE}(p<$ 0.05 ) compared to those of the induction-only group (mice exposed to DNCB instead of BDB; Fig. 2B).

$B D B$ suppresses the development of experimental AD. The skin lesions associated with $\mathrm{AD}$ are characterized by infiltration of various inflammatory cells (35). Therefore, we measured whether BDB treatment alleviates the degree of inflammatory cell infiltration in the ears of mice with 
(A)

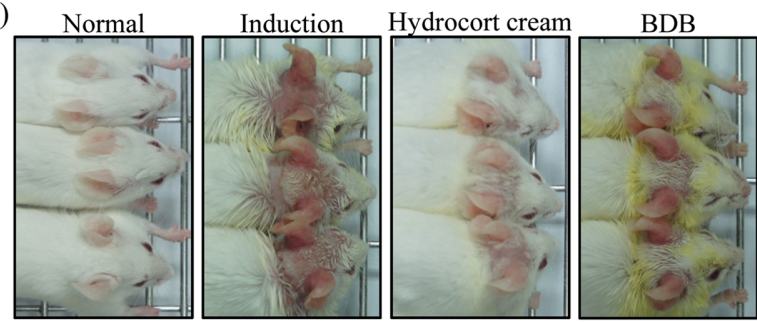

(B)

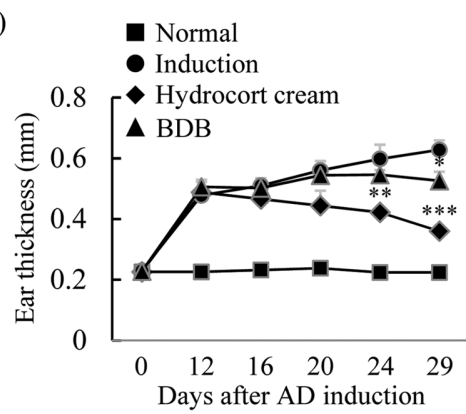

(C)

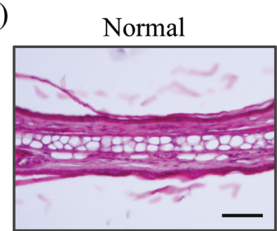

Induction

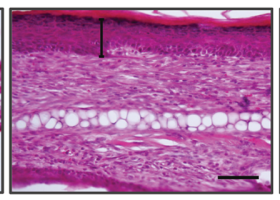

BDB

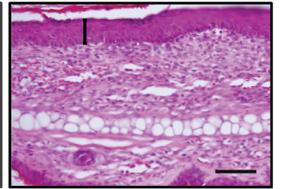

(D)

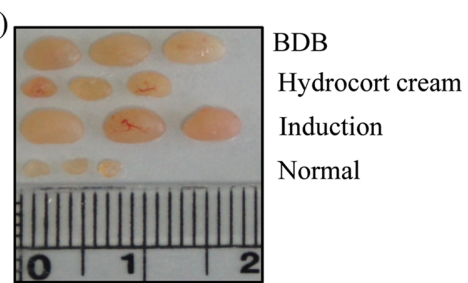

Fig. 3. 3-Bromo-4,5-dihydroxybenzaldehyde (BDB) suppresses experimental atopic dermatitis (AD). (A) Macroscopic views of the ears and (B) ear thickness measured on days 7, 19, 23, 27, 31, and 36. (C) Paraffin-embedded sections of ear tissue were stained with hematoxylin and eosin. (D) The lymph nodes (LNs) were photographed to record morphologic changes. $\mathrm{N}=5$ mice per group. Scale bar $=$ $0.1 \mathrm{~mm}$. Values represent the mean \pm SD. ${ }^{*} p<0.05 ;{ }^{* *} p<0.01$ and ${ }^{* * *} p<0.001$ compared to mice stimulated with $2,4-$ dinitrochlorobenzene (DNCB) alone (induction-only group).

experimental AD. We also tested skin swelling as a measure of $\mathrm{AD}$ progression. We found that cutaneous edema in BDB-treated mice reduced on day 36 compared with that of the induction-only mice $(p<0.05$; Fig. $3 \mathrm{~A}, 3 \mathrm{~B})$. We next examined the effect of BDB on the infiltration of inflammatory cells by $H \& E$ staining of ear tissue sections. Epidermal thickness and the degree of inflammatory cell infiltration were significantly lower in the BDB-treated group than in the induction-only group (Fig. 3C). LNs have a crucial role in cell-mediated immunity by regulating the activity of $\mathrm{T}$ and B-cells (36). Therefore, we examined morphologic changes in the LNs of AD mice. The LNs in mice in the induction-only group were swollen, whereas those in the BDB-treated mice were smaller (Fig. 3D).

$B D B$ inhibits LPS-induced IL-6 production in RAW $\mathbf{2 6 4 . 7}$ cells. To assess the anti-inflammatory effect of BDB, we examined the inhibitory activity of BDB on LPS-induced IL-6 production, an important pro-inflammatory cytokine $(10,11)$, in RAW 264.7 cells. To confirm the effect of BDB, we simultaneously determined cell viability at various concentrations of BDB. We found that BDB was not cytotoxic at the tested concentrations (Fig. 4). Next, we assayed the inhibitory effect of BDB on LPS-induced IL-6 production. As shown in Fig. 4, BDB inhibited the production of IL- 6 in a dosedependent manner at concentrations of 25,50 , and $100 \mu \mathrm{M}$.

BDB inhibits NF-KB phosphorylation in LPS-stimulated RAW 264.7 cells. LPS presentation on macrophages may mediate the activation of the NF- $\kappa \mathrm{B}$ pathway

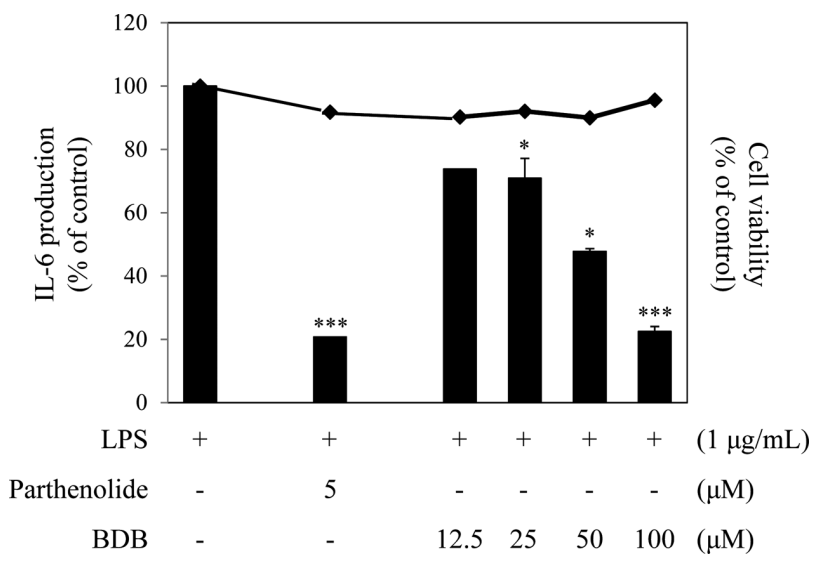

Fig. 4. Effects of 3-bromo-4,5-dihydroxybenzaldehyde (BDB) on cell viability and interleukin-6 (IL-6) production in RAW 264.7 murine macrophages. Cells $\left(1.5 \times 10^{5}\right.$ cells $\left./ \mathrm{mL}\right)$ were pre-incubated with DMEM/10\% FBS for $18 \mathrm{hr}$, after which IL- 6 production was analyzed from the supernatants of cells stimulated with lipopolysaccharide (LPS; $1 \mu \mathrm{g} / \mathrm{mL}$ ) in the absence or presence of BDB for $24 \mathrm{hr}(12.5$ to $100 \mu \mathrm{M})$. IL-6 production was determined by ELISA. The measurement of IL- 6 was obtained in triplicate. Error bars indicate \pm SD. ${ }^{*} p<0.05,{ }^{* * *} p<0.001$ compared with LPS-positive control.

$(21,22,37)$, leading to the generation of pro-inflammatory cytokines, including IL- 6 and TNF- $\alpha$. We determined the phosphorylation status of $\mathrm{NF}-\kappa \mathrm{B}$ with and without BDB treatment by western blot analysis. BDB inhibited LPSinduced phosphorylation of NF- $\mathrm{KB}$ at concentrations of 50 
and $100 \mu \mathrm{M}$ (Fig. 5). These results suggest that the inhibitory effect of BDB on the production of IL- 6 occurs through inhibition of NF- $\mathrm{kB}$ phosphorylation.

BDB inhibits STAT1 phosphorylation in LPS-stimulated RAW 264.7 cells. The STATs are a family of nuclear proteins that mediate the action of several cytokines, including ILs and IFNs. Suppressor of cytokine signaling 1 (SOCS1) is a negative-feedback regulator of Janus kinase (JAK)-STAT signaling $(25,38)$. Therefore, we examined the effect of BDB on the activation of STAT1 and SOCS in LPS-treated RAW 264.7 cells. LPS induced STAT1 phosphorylation at both Tyr701 and Ser727 residues, and had no effect on SOCS activation. BDB $(100 \mu \mathrm{M})$ strongly inhibited the phosphorylation of STAT1 at Tyr701 (Fig. 6).

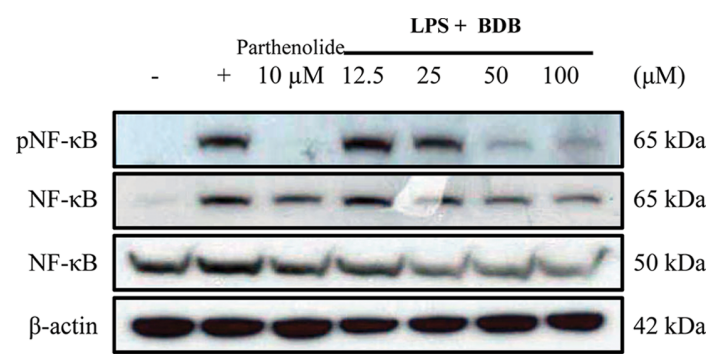

Fig. 5. Effects of 3-bromo-4,5-dihydroxybenzaldehyde (BDB) on NF- $\kappa B$ phosphorylation in lipopolysaccharide (LPS)-stimulated RAW 264.7 macrophages. RAW 264.7 cells $\left(5.0 \times 10^{5}\right.$ cells $\left./ \mathrm{mL}\right)$ were pre-incubated for $18 \mathrm{hr}$. Cells were pretreated with BDB $(12.5$ to $100 \mu \mathrm{M})$ for $120 \mathrm{~min}$, and then stimulated with LPS $(1 \mu \mathrm{g} / \mathrm{mL}$ ) for $5 \mathrm{~min}$. Expression of NF- $\mathrm{kB}$ phosphorylation (p65 and $p 50)$ and $\beta$-actin was determined by western blotting of whole cell lysates with the indicated antibodies. The data are representative of two independent experiments.

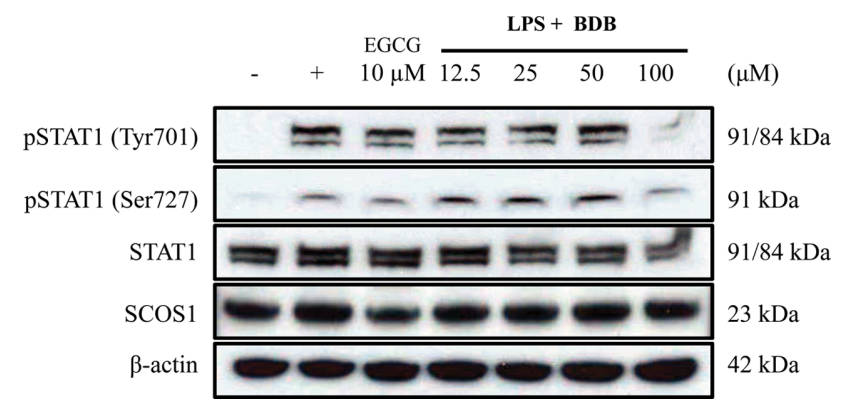

Fig. 6. Effects of 3-bromo-4,5-dihydroxybenzaldehyde (BDB) on the phosphorylation of STAT1 at Tyr701 and Ser727 residues in lipopolysaccharide (LPS)-stimulated RAW 264.7 macrophages. RAW 264.7 cells $\left(5.0 \times 10^{5}\right.$ cells $\left./ \mathrm{mL}\right)$ were pre-incubated for $18 \mathrm{hr}$. Cells were pretreated with BDB $(12.5$ to $100 \mu \mathrm{M})$ for $120 \mathrm{~min}$ and stimulated with LPS $(1 \mu \mathrm{g} / \mathrm{mL})$ for $120 \mathrm{~min}$. Expression of phosphorylated STAT1 at Tyr701 and Ser727, STAT1, SOCS1, and $\beta$-actin was determined by western blotting of whole cell lysates with the indicated antibodies.

\section{DISCUSSION}

Marine plants have been the focus of recent studies in the search for active components for use in the pharmaceutical and functional food industries (26-29). BDB is a compound mainly isolated from marine red algae, including $P$. morrowii and P. urceolata.

In this study, we demonstrated that BDB, a natural bromophenol compound, inhibits various inflammatory responses in mice and in murine macrophages. To induce experimental $\mathrm{AD}$, mice were sensitized by applying $\mathrm{DNCB}$ to the abdomen, and then re-sensitized by applying DNCB to the ears every other day. IgE is an important therapeutic target for $\mathrm{AD}$, as it is the major activator of mast cells (34). Furthermore, IgE signaling through FceRI can release histamine, tryptase, and cytokines from mast cells, which leads to potent induction of edema and itching $(39,40)$. Therefore, we tested whether BDB can reduce serum IgE hyperproduction and cutaneous edema. BDB treatment reduced the levels of $\operatorname{IgE}$ and edema compared with induction only. H\&E staining of ear tissue showed that BDB treatment alleviated the infiltration of inflammatory cells compared with induction alone. The LNs play an important role in regulating immune responses and contain a variety of immune cells. In addition, enlarged LNs are a key indicator of abnormalities in the immune system (41). We investigated the morphology of the LNs in an experimental AD model. The induction-only group had markedly enlarged LNs, whereas the LNs of BDB-treated mice were smaller. It is not yet clear why BDB has such strong anti-inflammatory effects. Thus, we are currently trying to identify the interrelationships between BDB and regulatory $\mathrm{T}$ cells.

To investigate the anti-inflammatory effect and the mechanisms of action of BDB in vitro, we stimulated RAW 264.7 cells with LPS, an inducer of the innate immune response. LPS binds to the myeloid differentiation factor-2 (MD-2)/ TLR4 complex, activates a downstream signaling pathway, and releases various inflammatory mediators, including IL6 , inducible nitric oxide synthase (iNOS), and TNF- $\alpha$. We examined the inhibitory effect of BDB on LPS-induced IL6 production. BDB inhibited the production of IL- 6 in a dose-dependent manner (Fig. 4). Several previous reports have shown that NF- $\mathrm{kB}$ and STAT1 act as important upstream signaling molecules for the production of IL-6 in LPS-stimulated monocytes or macrophages. In a previous study, we reported that N-tosyl-L-phenylalanine chloromethyl ketone, a specific inhibitor of NF- $\mathrm{kB}$ signaling, affects IL-6 production (23). NF- $\mathrm{KB}$ inhibition attenuates TLR4 expression in LPS-treated THP1 monocytes (22). Choi et al. (42) reported that azithromycin attenuated LPS-induced IL-6 production through inhibition of NF- $\mathrm{\kappa B}$, STAT1, and STAT3 in murine macrophages. Luu et al. (43) also reported that TLR4 induces phosphorylation of STAT1 at Ser727, and direct activation of STAT1 by TLR signaling is crucial 
for the involvement of STAT1 in TLR-induced inflammation. In the present study, BDB strongly inhibited LPSinduced phosphorylation of NF-kB and STAT1 (Tyr701). Similarly, Cho et al. reported that myricetin suppressed IL6 and other pro-inflammatory mediators by activating NF$\kappa \mathrm{B}$ and STAT1 in LPS-stimulated RAW 264.7 murine macrophages (44). Therefore, our results show that the inhibitory effect of BDB on the production of IL- 6 occurs through inhibition of the phosphorylation of NF-kB and STAT1.

In $\mathrm{AD}$, macrophages are known to accumulate in acutely and chronically inflamed skin. Macrophages also exert proinflammatory functions, such as antigen-presenting phagocytosis and the production of inflammatory cytokines and chemokines that stimulate new capillary growth, collagen synthesis, and fibrosis $(45,46)$. Monocytes are important macrophage precursor cells that are involved in AD-related skin inflammation. Monocytes invade the dermis and differentiate into macrophages, which can also act as antigen-presenting cells $(47,48)$ Although the inter-relationships between BDB and regulatory T-cells are of interest to the field and are currently under investigation, the focus of the present study was to show that BDB alleviates inflammatory responses in macrophages and atopic dermatitis mice.

In conclusion, our results reveal that $\mathrm{BDB}$, a component of $P$. morrowii, alleviated inflammatory responses in an atopic dermatitis mouse model and in LPS-stimulated RAW 264.7 murine macrophages. These results suggest that treatment with BDB may be a useful therapeutic strategy for allergic inflammation such as $\mathrm{AD}$.

\section{ACKNOWLEDGMENTS}

This study was supported by the National Research Foundation of Korea (NRF) grant funded by the Korea government (MSIP) (2016R1A2B4014050).

\section{CONFLICT OF INTEREST}

The authors have no conflicts of interest to declare.

Received July 19, 2017; Revised August 21, 2017; Accepted September 14, 2017

\section{REFERENCES}

1. Leung, D.Y., Boguniewicz, M., Howell, M.D., Nomura, I. and Hamid, Q.A. (2004) New insights into atopic dermatitis. $J$. Clin. Invest., 113, 651-657.

2. Li, C., Lasse, S., Lee, P., Nakasaki, M., Chen, S.W., Yamasaki, K., Gallo, R.L. and Jamora, C. (2010) Development of atopic dermatitis-like skin disease from the chronic loss of epidermal caspase-8. Proc. Natl. Acad. Sci. U.S.A., 107, 22249-22254.

3. Nystad, W., Roysamb, E., Magnus, P., Tambs, K. and Harris, J.R. (2005) A comparison of genetic and environmental vari- ance structures for asthma, hay fever and eczema with symptoms of the same diseases: a study of Norwegian twins. Int. J. Epidemiol., 34, 1302-1309.

4. Kawakami, T., Ando, T., Kimura, M., Wilson, B.S. and Kawakami, Y. (2009) Mast cells in atopic dermatitis. Curr. Opin. Immunol., 21, 666-678.

5. Kitamura, Y. and Ito, A. (2005) Mast cell-committed progenitors. Proc. Natl. Acad. Sci. U.S.A., 102, 11129-11130.

6. Glimcher, L.H. and Murphy, K.M. (2000) Lineage commitment in the immune system: The T helper lymphocyte grows up. Genes Dev., 14, 1693-1711.

7. Ouyang, W., Ranganath, S.H., Weindel, K., Bhattacharya, D., Murphy, T.L., Sha, W.C. and Murphy, K.M. (1998) Inhibition of Th1 development mediated by GATA-3 through an IL-4independent mechanism. Immunity, 9, 745-755.

8. Romagnani, S. (2000) The role of lymphocytes in allergic disease. J. Allergy Clin. Immunol., 105, 399-408.

9. Elson, C.O., Cong, Y., Brandwein, S., Weaver, C.T., McCabe, R.P., Mahler, M., Sundberg, J.P. and Leiter, E.H. (1998) Experimental models to study molecular mechanisms underlying intestinal inflammation. Ann. N. Y. Acad. Sci., 859, 85-95.

10. Tanaka, T., Narazaki, M. and Kishimoto, T. (2014) IL-6 in inflammation, immunity, and disease. Cold Spring Harb. Perspect. Biol., 6, a016295.

11. Barnes, T.C., Anderson, M.E. and Moots, R.J. (2011) The many faces of interleukin-6: the role of IL-6 in inflammation, vasculopathy, and fibrosis in systemic sclerosis. Int. J. Rheumatol., 2011, 721608.

12. Okiyama, N., Sugihara, T., Iwakura, Y., Yokozeki, H., Miyasaka, N. and Kohsaka, H. (2009) Therapeutic effects of interleukin- 6 blockade in a murine model of polymyositis that does not require interleukin-17A. Arthritis Rheum., 60, 2505-2512.

13. Fujimoto, M., Serada, S., Mihara, M., Uchiyama, Y., Yoshida, H., Koike, N., Ohsugi, Y., Nishikawa, T., Ripley, B., Kimura, A., Kishimoto, T. and Naka, T. (2008) Interleukin-6 blockade suppresses autoimmune arthritis in mice by the inhibition of inflammatory Th17 responses. Arthritis Rheum., 58, 37103719 .

14. Alonzi, T., Fattori, E., Lazzaro, D., Costa, P., Probert, L., Kollias, G., De Benedetti, F., Poli, V. and Ciliberto, G. (1998) Interleukin 6 is required for the development of collageninduced arthritis. J. Exp. Med., 187, 461-468.

15. Caiello, I., Minnone, G., Holzinger, D., Vogl, T., Prencipe, G., Manzo, A., De Benedetti, F. and Strippoli, R. (2014) IL-6 amplifies TLR mediated cytokine and chemokine production: implications for the pathogenesis of rheumatic inflammatory diseases. PLOS ONE, 9, e107886.

16. Nakahara, H., Song, J., Sugimoto, M., Hagihara, K., Kishimoto, T., Yoshizaki, K. and Nishimoto, N. (2003) Antiinterleukin-6 receptor antibody therapy reduces vascular endothelial growth factor production in rheumatoid arthritis. Arthritis Rheum., 48, 1521-1529.

17. Akira, S. and Takeda, K. (2004) Toll-like receptor signalling. Nat. Rev. Immunol., 4, 499-511.

18. Park, B.S., Song, D.H., Kim, H.M., Choi, B.S., Lee, H. and Lee, J.O. (2009) The structural basis of lipopolysaccharide recognition by the TLR4-MD-2 complex. Nature, 458, 11911195.

19. Hoshino, K., Takeuchi, O., Kawai, T., Sanjo, H., Ogawa, T., 
Takeda, Y., Takeda, K. and Akira, S. (1999) Cutting edge: Toll-like receptor 4 (TLR4)-deficient mice are hyporesponsive to lipopolysaccharide: evidence for TLR4 as the Lps gene product. J. Immunol., 162, 3749-3752.

20. Chow, J.C., Young, D.W., Golenbock, D.T., Christ, W.J. and Gusovsky, F. (1999) Toll-like receptor-4 mediates lipopolysaccharide-induced signal transduction. J. Biol. Chem., 274, 10689-10692.

21. Kawai, T. and Akira, S. (2007) Signaling to NF-kB by Tolllike receptors. Trends Mol. Med., 13, 460-469.

22. Wan, J., Shan, Y., Fan, Y., Fan, C., Chen, S., Sun, J., Zhu, L., Qin, L., Yu, M. and Lin, Z. (2016) NF-kB inhibition attenuates LPS-induced TLR4 activation in monocyte cells. Mol. Med. Rep., 14, 4505-4510.

23. Kang, N.J., Han, S.C., Kang, G.J., Koo, D.H., Koh, Y.S., Hyun, J.W., Lee, N.H., Ko, M.H., Kang, H.K. and Yoo, E.S. (2015) Diphlorethohydroxycarmalol inhibits interleukin-6 production by regulating NF- $\mathrm{BB}$, STAT5 and SOCS1 in lipopolysaccharide-stimulated RAW264.7 cells. Mar. Drugs, 13, 2141-2157.

24. Gorina, R., Font-Nieves, M., Marquez-Kisinousky, L., Santalucia, T. and Planas, A.M. (2011) Astrocyte TLR4 activation induces a proinflammatory environment through the interplay between MyD88-dependent NFKB signaling, MAPK, and Jak1/Stat1 pathways. Glia, 59, 242-255.

25. Kaplan, M.H. (2013) STAT signaling in inflammation. JAKSTAT, 2, e24198.

26. Chae, D., Manzoor, Z., Kim, S.C., Kim, S., Oh, T.H., Yoo, E.S., Kang, H.K., Hyun, J.W., Lee, N.H., Ko, M.H. and Koh, Y.S. (2013) Apo-9'-fucoxanthinone, isolated from Sargassum muticum, inhibits $\mathrm{CpG}$-induced inflammatory response by attenuating the mitogen-activated protein kinase pathway. Mar. Drugs, 11, 3272-3287.

27. Han, S.C., Kang, G.J., Ko, Y.J., Kang, H.K., Moon, S.W., Ann, Y.S. and Yoo, E.S. (2012) External application of fermented olive flounder (Paralichthys olivaceus) oil alleviates inflammatory responses in 2,4-dinitrochlorobenzeneinduced atopic dermatitis mouse model. Toxicol. Res., 28, 159-164.

28. Jo, W.S., Choi, Y.J., Kim, H.J., Nam, B.H., Lee, G.A., Seo, S.Y., Lee, S.W. and Jeong, M.H. (2010) Methanolic extract of Asterina pectinifera inhibits LPS-induced inflammatory mediators in murine macrophage. Toxicol. Res., 26, 37-46.

29. Kang, N.J., Koo, D.H., Kang, G.J., Han, S.C., Lee, B.W., Koh, Y.S., Hyun, J.W., Lee, N.H., Ko, M.H., Kang, H.K. and Yoo, E.S. (2015) Dieckol, a component of ecklonia cava, suppresses the production of $\mathrm{mdc} / \mathrm{ccl} 22$ via down-regulating STAT1 pathway in interferon- $\gamma$ stimulated $\mathrm{HaCaT}$ human keratinocytes. Biomol. Ther. (Seoul), 23, 238-244.

30. Hyun, Y.J., Piao, M.J., Zhang, R., Choi, Y.H., Chae, S. and Hyun, J.W. (2012) Photo-protection by 3-bromo-4, 5-dihydroxybenzaldehyde against ultraviolet B-induced oxidative stress in human keratinocytes. Ecotoxicol. Environ. Saf., 83, 71-78.

31. Kim, S.Y., Kim, S.R., Oh, M.J., Jung, S.J. and Kang, S.Y. (2011) In vitro antiviral activity of red alga, Polysiphonia morrowii extract and its bromophenols against fish pathogenic infectious hematopoietic necrosis virus and infectious pancreatic necrosis virus. J. Microbiol., 49, 102-106.

32. Hirai, A., Minamiyama, Y., Hamada, T., Ishii, M. and Inoue,
M. (1997) Glutathione metabolism in mice is enhanced more with hapten-induced allergic contact dermatitis than with irritant contact dermatitis. J. Invest. Dermatol., 109, 314-318.

33. Traidl, C., Jugert, F., Krieg, T., Merk, H. and Hunzelmann, N. (1999) Inhibition of allergic contact dermatitis to DNCB but not to oxazolone in interleukin-4-deficient mice. J. Invest. Dermatol., 112, 476-482.

34. Levin, T.A., Ownby, D.R., Smith, P.H., Peterson, E.L., Williams, L.K., Ford, J., Young, P. and Johnson, C.C. (2006) Relationship between extremely low total serum IgE levels and rhinosinusitis. Ann. Allergy Asthma Immunol., 97, 650652.

35. de Vries, I.J., Langeveld-Wildschut, E.G., van Reijsen, F.C., Bihari, I.C., Bruijnzeel-Koomen, C.A. and Thepen, T. (1997) Nonspecific T-cell homing during inflammation in atopic dermatitis: expression of cutaneous lymphocyte-associated antigen and integrin $\alpha \mathrm{E} \beta 7$ on skin-infiltrating $\mathrm{T}$ cells. J. Allergy Clin. Immunol., 100, 694-701.

36. Debes, G.F., Bonhagen, K., Wolff, T., Kretschmer, U., Krautwald, S., Kamradt, T. and Hamann, A. (2004) CC chemokine receptor 7 expression by effector/memory CD4+ T cells depends on antigen specificity and tissue localization during influenza A virus infection. J. Virol., 78, 7528-7535.

37. Kim, M.Y., Kim, J.H. and Cho, J.Y. (2014) Cytochalasin B modulates macrophage-mediated inflammatory responses. Biomol. Ther. (Seoul), 22, 295-300.

38. O'Shea, J.J. and Plenge, R. (2012) JAK and STAT signaling molecules in immunoregulation and immune-mediated disease. Immunity, 36, 542-550.

39. Schwartz, L.B. (2004) Effector cells of anaphylaxis: mast cells and basophils. Novartis Found. Symp., 257, 65-74; discussion 74-79, 98-100, 276-285.

40. Stone, K.D., Prussin, C. and Metcalfe, D.D. (2010) IgE, mast cells, basophils, and eosinophils. J. Allergy Clin. Immunol., 125, S73-S80.

41. Singer, P.A., McEvilly, R.J., Noonan, D.J., Dixon, F.J. and Theofilopoulos, A.N. (1986) Clonal diversity and T-cell receptor beta-chain variable gene expression in enlarged lymph nodes of MRL-lpr/lpr lupus mice. Proc. Natl. Acad. Sci. U.S.A., 83, 7018-7022.

42. Choi, E.Y., Jin, J.Y., Choi, J.I., Choi, I.S. and Kim, S.J. (2014) Effect of azithromycin on Prevotella intermedia lipopolysaccharide-induced production of interleukin-6 in murine macrophages. Eur. J. Pharmacol., 729, 10-16.

43. Luu, K., Greenhill, C.J., Majoros, A., Decker, T., Jenkins, B.J. and Mansell, A. (2014) STAT1 plays a role in TLR signal transduction and inflammatory responses. Immunol. Cell Biol., 92, 761-769.

44. Cho, B.O., Yin, H.H., Park, S.H., Byun, E.B., Ha, H.Y. and Jang, S.I. (2016) Anti-inflammatory activity of myricetin from Diospyros lotus through suppression of NF- $\mathrm{kB}$ and STAT1 activation and Nrf2-mediated HO-1 induction in lipopolysaccharide-stimulated RAW264.7 macrophages. Biosci. Biotechnol. Biochem., 80, 1520-1530.

45. Kasraie, S. and Werfel, T. (2013) Role of macrophages in the pathogenesis of atopic dermatitis. Mediators Inflamm., 2013, 942375.

46. Mirza, R., DiPietro, L.A. and Koh, T.J. (2009) Selective and specific macrophage ablation is detrimental to wound healing 
in mice. Am. J. Pathol., 175, 2454-2462.

47. Novak, N., Bieber, T. and Leung, D.Y. (2003) Immune mechanisms leading to atopic dermatitis. J. Allergy Clin. Immunol., 112, S128-S139.

48. Vestergaard, C., Just, H., Baumgartner Nielsen, J., Thestrup-
Pedersen, K. and Deleuran, M. (2004) Expression of CCR2 on monocytes and macrophages in chronically inflamed skin in atopic dermatitis and psoriasis. Acta Derm. Venereol., 84, 353358. 